\title{
Interjurisdictional Capitalization of a New Metro Line on Housing Values
}

\author{
Claudio A. Agostini* and Gastón A. Palmucci ${ }^{\dagger}$
}

February 2010

\begin{abstract}
Many governments continue constructing new subway lines with the goal of reducing congestion and pollution in large cities. Besides the potential global effects on reducing negative externalities in the city, there are some local positive effects in terms of lower commuting time and distance for residents living close to the subway stations. These benefits of the public transport services should capitalize totally or partially on housing prices. Most of the empirical work has estimated the effects on housing prices after the public transit infrastructure is operating and implicitly assumed homogeneous capitalization across jurisdictions. However, due to differences on local public goods provision and residents' characteristics across jurisdictions, two identical housing units located at the same distance to the nearest metro station but in different local markets would not necessarily have the same degree of capitalization.

Using parametric and non-parametric methods and transaction data for Santiago, Chile, we estimate the anticipated capitalization of a new metro line across counties in the city. The results show significant anticipated effects, between $3.6 \%$ and $5.3 \%$, and also large interjurisdictional differences in capitalization degrees, ranging between $-6 \%$ and $40 \%$.
\end{abstract}

Keywords: Metro, Capitalization, Housing Prices

JEL: H73, H54, R21, R53

*Ilades-Universidad Alberto Hurtado, Santiago Chile. Email: agostin@uahurtado.cl

†University of Wisconsin, Madison. Email:palmucci@wisc.edu. 


\section{Introduction}

In an effort to reduce vehicle congestion and reduce commuting times, many cities in the world have been investing large amounts in public transportation infrastructure. The city of Santiago is not an exception in this trend and large investments has been made in extending the metro network over the last 5 years. These transit expansions generate an opportunity for mobile households who use public transport to move to areas in the city where access has improved (Baum-Snow and Kahn (2000)). As a result, and also because housing supply close to public transit access is fixed, the benefits of the public transport services should capitalize totally or in part on land property and housing prices (Henneberry, 1998; Oakland, 1987; Rubinfeld, 1987).Despite this prediction the empirical literature on the effect of proximity to public transport access on property prices is mixed in its findings. The evidence provided by Debrezion, Pels and Rietveld (2003), Dewees (1976), Grass (1992), Bajic (1983), Voith (1991, 1993), Al-Mosaind et al. (1993), Cervero (1994) and Damm et al. (1980) shows positive effects in the case of trains and subways in different cities of the USA and Canada; while the results of Dornbusch (1975), Armstrong (1994), Bowes and Ihlanfeldt (2001), and Landis et al. (1995) show negative effects for trains. Some other studies have found no effect at all. For example, Gatzlaff and Smith (1993) found no effects of having announced the new train system in Miami; Redfearn (2009) found no capitalization of access to light rail in Los Angeles; and Debrezion et al. (2007) report no consistent relationship between proximity to railway stations and property values in a review of empirical studies.

Most of the previous empirical work estimates the effects on housing prices after the public transit infrastructure is operating and implicitly assumes homogeneous capitalization across jurisdictions. There exists some evidence of capitalization occurring before a new transit facil-

ity operating (McMillen and McDonald (2004); Damm et al. (1980); Agostini and Palmucci (2008); and McDonald and Osuji (1995)) and this work contributes to that literature analyzing the anticipated effect of the announcement of a new metro line in the city of Santiago in Chile. There is also some evidence of significant variation in property tax capitalization across municipalities, showing that house prices vary systematically with jurisdictions tax rates and tax 
bases (Goodman (1983)), which suggests that the capitalization of better transit access might also vary by jurisdiction. In fact, the impact of rail station proximity on property values varies with distance from the station, distance to downtown, and also with the median income of the neighborhood (Bowes and Ihlanfeldt (op.cit.)). In this paper we explore the interjurisdictional capitalization of the new metro line across different counties in the city of Santiago, dropping for this purpose the standard assumption of common prices across space usually used in hedonic regressions.

One of the main challenges when estimating capitalization is to isolate tax effects from public goods effects (Palmon and Smith (1998)). In the case of Chile, property taxes are set and collected at a federal level. Therefore, there is no tax rate variation across jurisdictions, which allows us to isolate the effects of public goods on housing prices. Exploiting this institutional feature of the Chilean tax system and using parametric and non-parametric methods we are able to estimate the anticipated effects of the new metro line across counties in Santiago.

Our results show that the degree of capitalization depends not only on the distance from the apartment to the nearest station but also on the combination of county characteristics and local public goods. More specifically, two equivalent housing units located at the same distance to the nearest station but in different counties present different degrees of capitalization. In general, the results suggest significant interjurisdictional differences in capitalization, ranging from $-15.3 \%$ to $37.8 \%$ after the construction of the new metro line was announced and between $-15 \%$ and $56 \%$ after the announcement of the stations location. If only the housing units located within a 1,000 meters range from the nearest metro station are considered, the differences in capitalization across counties vary between $6 \%$ and $40.9 \%$ for the construction announcement and between $6.9 \%$ and $50 \%$ for location of the stations announcement.

The remaining of the paper is organized as follows. Section 2 provides a brief description of the Santiago metro system, particularly with respect to the new Line 4 . Section 3 discusses the capitalization of public transit services on housing prices and differences across jurisdictions. Section 4 explains the empirical strategy and discusses the underlying identifying assumptions. Section 5 describes the data used. Section 6 presents the empirical results. Finally, Section 7 
concludes.

\section{The Santiago Metro System}

In 1969, the Santiago metro network was designed as the central axis of the city transport system. The original master plan included 7 lines which would be built based on the demand evolution across the city. In 1975, Line 1 (Moneda-San Pablo) started operating, which was later on extended in 1980 (to Escuela Militar). Then, Lines 2 and 5 started operating in 1987 and 1997 respectively. These three lines cover $40.2 \mathrm{~km}$ railways, 52 stations, and in 2004, an average 866,700 daily trips were registered on weekdays. Figure N 1 shows a map with the location and scope of the Santiago Metro Lines.

Figure 1: Metro Network

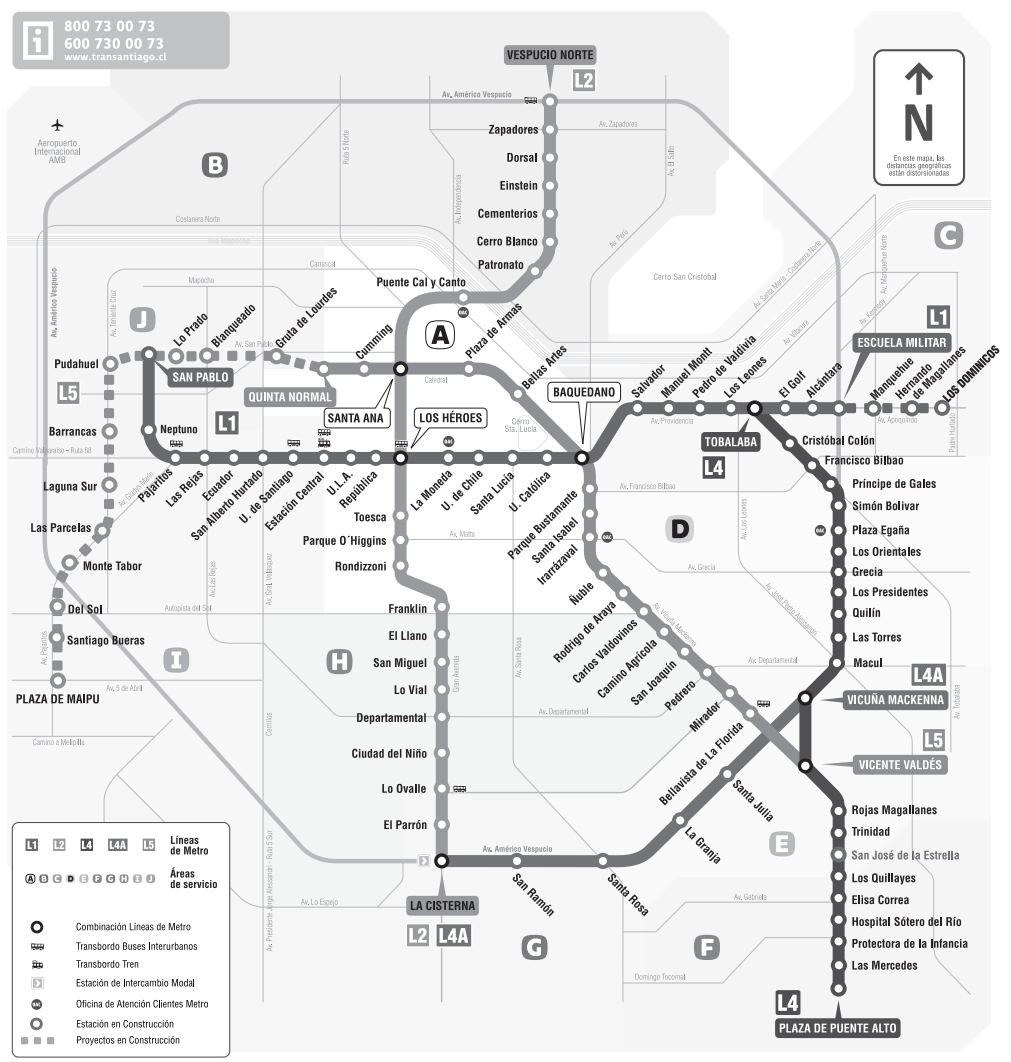

In May 2001 the government announced the construction of Line 4, which was expected to start partially operating in December 2005 and fully in March 2006. The new Line involved 33 
$\mathrm{km}$ railways with 22 stations across 7 counties. The demand projection reflected an increase in the average daily circulation flow of around 324,000 passengers.

\section{Public Goods, Transport Cost and Housing Prices}

Location of a housing unit determines the transport cost residents face in order to travel to their work and study places. As a result, housing prices should reflect the transport cost savings in terms of time and distance to the main job markets and shopping places in a city (Von Thnen (1863), Alonso (1964), Mills (1967) and Muth (1969)). Location also determines the level of local public goods residents can consume. Therefore, the market price of a housing unit also reflects the marginal value to be paid for by all potential purchasers of units located in an area with access to a determined set of public goods (Yinger (1982), Rubinfeld (1987)).

The new metro Line 4 is a semi-public good that reduces travel costs to the main workplaces and shopping centers of Santiago. One of the expected effects is an increase on housing demand in the 7 counties covered by Line 4, especially in the geographical areas close to the Metro stations. Because housing units supply in the relevant area is fixed, at least in the short run, the demand increase should produce an increase in the price of housing units located near Line 4 stations, capitalizing up to some extent the benefits of a better access. The degree of heterogeneity of local public goods preferences determines the degree of capitalization and the empirical evidence shows that its average value tends to capitalize importantly on housing prices (Gramlich and Rubinfeld, 1982). The specific degree of capitalization depends on the distance of each housing unit and properties to the new metro stations and the socioeconomic characteristics of the residents. The main reason for the latter is that the production of several local public goods supplied by a county is affected by the distribution of sociological attributes within the population, like income, poverty, and education (Gravel et al (2006)). Additionally, proximity to a metro station, for example, is of higher value to low-income residential neighborhoods than to high income residential neighborhoods because low income residents tend to rely

on public transportation and thus attached higher value to living close to the station (Nelson 
More general, individual socioeconomic characteristics determine the willingness to pay for some specific housing attributes. For example, heavy metro users are willing to pay a higher price than light metro users for a house close to the metro station. Unfortunately, there is no available information allowing us to observe the socioeconomic characteristics of individuals who choose to buy a house or an apartment near the new metro line. However, a Tiebout sorting mechanism leads to interjurisdictional differences in tax rates relative to public goods and services being capitalized into property values (Hamilton (1976)). In the case of Chile, all taxes are set at the federal level and there are no tax rate differences across jurisdictions. Therefore, different capitalization degrees would reflect differences in local public goods across counties within a city like Santiago, including access to the new metro line.

As a result of existing differences on socioeconomic characteristics and local public goods provision across counties within Santiago, two identical housing units located at the same distance to the nearest metro station but in different counties (local markets) would not necessarily have the same degree of capitalization. More generally, housing is a bundled good and markets clear locally with no single implicit price for individual attributes existing globally (Readfearn (2009)). The goal, therefore, is to estimate the different degrees of capitalization of the new Line 4 across the different counties it serves.

The model generally used to study housing price determinants is the hedonic price model developed by Rosen (1974). Using this methodology, the market price of a housing unit is regressed on vector of characteristics: structural (number of bedrooms, bathrooms, parking lots, age, etc.), neighborhood (socioeconomic characteristics such as average income, delinquency rates) and property taxes and the local supply of public goods (hospitals, rubbish collection). The estimated coefficients represent the reduce-form market valuations of the individual characteristics. ${ }^{1}$ In broad terms, the house price equation to be estimated is as follow:

\footnotetext{
${ }^{1}$ The hedonic prices represent the envelope of consumer bid and producer supply functions. When producer supply functions are identical demand shifts will identify a supply curve and when consumer bid functions are identical supply shifts will identify the demand curve.
} 


$$
P_{i, t}=\alpha+\beta X_{i, t}+\gamma L_{i, t}+\delta D_{i, t}+\tau t+\sum_{j=1}^{J} \eta_{j} C_{i, j}+\epsilon_{i, t}
$$

where the dependent variable, $P_{i, t}$ is the selling price of house $\mathrm{i}$ at time $\mathrm{t}, X_{i, t}$ is the housing attributes vector (including size, number of bathrooms, number of bedrooms and so forth), $L_{i, t}$ is the vector reflecting the neighborhood and other location features other than access to mass transit (such as green areas, shops, schools and clinics), $D_{i, t}$ is a vector for the relevant variables related to access, $C_{i, j}$ is a vector of location fixed effects, i.e. a vector of dummy variables equal to 1 if the housing unit is in county $j$ and 0 otherwise, $t$ is a time trend and, finally, $\epsilon_{i, t}$ is the error term capturing unobserved determinants of housing prices.

\section{Identification}

Using a hedonic price estimation of equation (1) and defining $D_{i, t}$ as the distance or the time it takes to reach the nearest station it is possible to estimate the consumer marginal value of access to the metro station, as it has been done extensively in the empirical literature. However, our purpose is to estimate the inter-county differences in the degree of capitalization of Line 4 before it started operating, i.e. we want to capture the anticipated future benefits the new line will bring about.

For this purpose, it is important to identify the two main milestones revealing information about the new Line 4. First, the government announced the construction of the new Line 4 in May 2001. Only the general line layout was announced and the location of the stations remained unknown at this date. Second, the government revealed the location of the future Line 4 metros stations in December 2001. Henceforth, we shall refer to the first piece of information as the Announcement and to the second as the Basic Engineering Project or Engineering indistinctly.

If consumers are rational, the capitalization of the new metro line on housing prices should occur partially at the Announcement stage due to the uncertainty related to the location of the new stations, and then fully immediately after the Basic Engineering Project (unless there is 
also uncertainty about the project never being finished).

Without loss of generality, let's think about the announcement moment. Define the $t-1$ period as the ex ante situation before the construction of Line 4 was announced and the ex post period. If capitalization occurs we would observed the price of a housing unit i increase from $P_{i, t-1}$ to $P_{i, t}$, everything else constant. In order to quantify the effect of the announcement on property prices we would need to compare the new price of a housing unit with the price it would have had if the metro line had not been built. (the counterfactual price). However, it is not feasible to observe both the factual and counterfactual price for each housing unit. The standard solution to this missing data problem is to rely on comparisons between different housing units and, under some identifying assumptions, estimate the average effect. One way to proceed is to compare property prices after the announcement of Line 4 with property prices before the announcement for an equivalent group of properties. This comparison, controlling for the effect of observable housing and location characteristics, leads to the following hedonic regression:

$$
P_{i, t}=\alpha+\beta X_{i, t}+\gamma L_{i, t}+\delta D_{i, t}+\tau t+\sum_{j=1}^{J} \eta_{1, j} C_{i, j}+\sum_{j=1}^{J} \eta_{2, j} C_{i, j} T_{t}+\epsilon_{i, t}
$$

where $T_{t}$ is a dummy variable equal to 1 after the treatment, i.e. announcement or basic engineering of new line 4 , and 0 otherwise. As before, $C_{i, j}$ is a dummy variable equal to 1 if unit $\mathrm{i}$ is in county $\mathrm{j}$ and 0 otherwise. The coefficient associated to the interaction $C_{i, j} T_{t}$ captures the average housing price change in county $\mathrm{j}$ due to the new information released about Line 4. This set of interaction terms allows to estimate differences in the degree of metro access capitalization. The identifying assumption for this before-after estimator is that the difference between the true post-treatment counterfactual and their pre-treatment property prices averages out to zero across all housing units affected by the announcement of the new metro line 4. In other words, the before-after estimator assumes that the unobservables are specific to a housing unit and fixed over time.

An alternative way is to compare a before-after estimate of property prices between two 
different housing groups: one whose prices are affected and one whose prices are unaffected by the new metro line. In order to implement this approach we split our sample into two groups: properties located within a 1,000 meters radio from the nearest metro station and properties located outside that radio. ${ }^{2}$ The comparison of these two housing groups leads to the following hedonic regression:

$$
\begin{aligned}
& P_{i, t}=\alpha+\beta X_{i, t}+\gamma L_{i, t}+\delta D_{i, t}+\tau t+\theta T_{t}+\pi D 1000_{i}+\sum_{j=1}^{J} \eta_{1, j} C_{i, j} \\
& \quad+\sum_{j=1}^{J} \eta_{2, j} C_{i, j} T_{t}+\sum_{j=1}^{J} \eta_{3, j} C_{i, j} T_{t} D 1000_{i}+\epsilon_{i, t}
\end{aligned}
$$

where D1000 is a dummy variable equal to 1 if the housing unit is within 1,000 meters of its closest metro station and 0 otherwise. The coefficient of the $C_{i, j} T_{t} D 1000$ interaction captures the average price change of the housing units located within 1,000 meters radio from the closest station with respect to units outside that radio in county $\mathrm{j}$ as result of the new information known in the market. The identifying assumption in this case is that the average change in property prices if line 4 would not have been built would be the same for affected and unaffected housing units.

\section{Data}

For the empirical analysis we use data from the Property Registrar of Santiago, which is. the agency where all Real Estate Property transactions in the city of Santiago must be registered to be valid. We had access to data on all transactions between December 2000 and March 2004. ${ }^{3}$ However, we were limited to only use the data for apartments because the available information on structural attributes of houses and commercial properties was very limited. The database contains 20,900 recorded transactions in 6 counties with access to the new metro line (Providencia, Las Condes, La Reina, Peñalolen, Ñuñoa, and La Florida) and for 6,857 apartments in the database the shortest distance to a metro station corresponds to the new

\footnotetext{
${ }^{2}$ The Origin-Destination Survey for Santiago in 2001 showed that around 90 percent of metro demand for each station comes from a 1,000 meter radius

${ }^{3}$ The data was kindly provided by Mapcity S.A.
} 
Line 4.

Each observation contains the apartment price, a set of variables describing its physical attributes and its geographical location (East-North coordinates). This last variable allows us to compute the walking distance from each apartment to each of the 44 metro stations, 52 clinics, 8 hospitals, 756 green areas, 582 schools, and 11 universities located in this area of the city.

Table 1 shows a summary statistics of the variables used in the estimation.

Table 1: Descriptive statistics

\begin{tabular}{l|cccc}
\hline Variables & Mean & Std. Deviation & Min & Max \\
\hline Price (UFs) & $2,715.1$ & $2,063.7$ & 108 & 38,053 \\
DFL2 tax benefit & 0.06 & 0.23 & 0 & 1 \\
Age & 7.82 & 11.57 & 0 & 91 \\
No. of bedrooms & 2.52 & 0.96 & 1 & 6 \\
No. of bathrooms & 1.90 & 0.73 & 1 & 6 \\
No. of storages & 0.63 & 0.52 & 0 & 8 \\
No. of parking lots & 0.68 & 0.74 & 0 & 6 \\
Elevator & 0.90 & 0.29 & 0 & 1 \\
Change in housing stock & 28,361 & 1,723 & 24,046 & 31,904 \\
Located on a side street & 0.60 & 0.49 & 0 & 1 \\
Located on a main avenue & 0.40 & 0.48 & 0 & 1 \\
Distance to nearest metro station (meters) & 1,212 & 1,223 & 2 & 9,490 \\
Distance to nearest hospital (meters) & 1,110 & 763 & 8 & 5,926 \\
Distance to nearest clinic (meters) & 523 & 483 & 0 & 4,630 \\
Distance to nearest school (meters) & 269 & 178 & 0 & 1,505 \\
Distance to nearest university (meters) & 1,102 & 1,057 & 5 & 6,777 \\
Distance to nearest green area (meters) & 289 & 173 & 15 & 1,251 \\
Announcement & 0.91 & 0.28 & 0 & 1 \\
Engineering & 0.77 & 0.42 & 0 & 1 \\
D1000 (dummy) & 0.59 & 0.49 & 0 & 1 \\
\hline & & & &
\end{tabular}

The dependent variable is the apartment transaction price measured in U.F. (Unidades de Fomento). ${ }^{4}$ The set of independent variables consists of three groups of variables. First, a set of variables capturing the structural characteristics of each apartment: number of bedrooms, number of bathrooms, whether there is a storage room in the building, elevator, number of parking lots, age of the building, whether it enjoys the DFL2 tax exemption and if the building

\footnotetext{
${ }^{4}$ Unidades de fomento (U.F.) is one of the readjustment systems authorized by the Central Bank of Chile, 1 UF equals $\mathrm{CH} \$ 20,858$ and US\$38.1 in January 2010. It is used to index prices relative to inflation.
} 
is located on a street or an avenue. ${ }^{5}$ Second, a set of variables measuring access to public and semi-public goods: distance to the nearest metro station, school, hospital, university, clinic, and green area. Third, a set of dummies equivalent to county fixed effects which capture neighborhood differences across the new Line 4 service area.

Additionally, based on the previous discussion about identification we include a set of dummy variables to isolate the access value to metro stations at different times and communes. The variable Announcement is a dummy equal to 1 if the transaction occurred after May 2001. The interactions between Announcement and the county dummies capture the average change in housing prices at the specific county as a result of the announcement of the new metro line. Since at that moment the location of the new stations was not revealed, we expect a larger fraction of capitalization after the Basic Engineering stage. The variable Engineering, a dummy equal to 1 if the transaction occurred after October 2001, captures the effect of the information on the engineering project being revealed, including number of stations and their specific location. As before, the interaction between Engineering and county dummies capture the average change in apartments price at the each specific county as result of revealing the location of the new metro stations. The coefficients on these last variables identify interjurisdictional differences in the degree of capitalization.

Finally, the variable D1000 is a dummy equal to 1 if the apartment is located within a 1 kilometer radius from its closest metro station. Its interaction with the variables Announcement and Engineering generate a difference-in-difference estimator for the impact of metro access of apartment prices.

\section{Parametric Results}

Table 2 presents the relevant results for the purpose of this paper of estimating equations (2) and (3). The equations are estimated with OLS and using the Huber-White estimator for the

\footnotetext{
${ }^{5}$ Decree Law 2 of 1959 (DFL2) establishes that income earned from the rental of houses and apartments smaller than 140 square meters is exempt from income tax and other taxes, and income from the sale of such properties is exempt from the capital gains tax. Additionally, property taxes are reduced by 50 percent for the first ten years.
} 
standard errors. As a baseline, we first estimate the effects of the new metro line information releases on apartment prices without considering intrajurisdictional differences. For this purpose, models (1) and (5) use the before-after estimator of equation (2) and models (3) and (7) the difference-in-difference estimator of equation (3). Then, models (2) and (4) add the interacted dummies to models (1) and (3) to estimate the degree of differential capitalization associated to the announcement of the construction of the new Line 4. Equivalently, models (6) and (8) add the interacted dummies to models (5) and (7) to estimate differences in capitalization across counties of the announcement of the stations location.

In order to focus on the main goal of the paper, we briefly discuss the results related to the effect on prices of the structural characteristics of the apartments and the access to public goods. The full set of results is reported in Table A.1 in the Appendix.

In general, the coefficients related to structural characteristics of the apartments: number of bedrooms and bathrooms, parking spaces, storage, and age have the expected signs and are statistically significant. The estimated coefficient for the variable elevator is negative but is not statistically different from zero. The effect of the DFL2 tax benefit is positive and statistically significant, showing that tax exemptions are also capitalized into apartment prices. Finally, a change in the housing stock has a negative and statistically significant effect on apartment prices, which reflects the impact of increasing supply on the local market equilibrium price, everything else constant. The estimated coefficients for the variables measuring the distance to the nearest clinic, hospital, school, university, and green area are not completely satisfactory, probably implying that in many cases controlling for the quality of public goods might be more important than distance.

The baseline specifications show that anticipated capitalization of the future benefits of the new Line 4 did occur, as the point estimators for Announcement and Engineering are positive and statistically significant. On average an apartment value appreciated between $3.6 \%$ and $5.3 \%$ after the Announcement and the Basic Engineering information was released respectively. Additionally, the results show that, in fact, apartments located within a 1,000 meters range from the nearest metro station increase their value more than the ones located farther away. 
The difference in appreciation between the two is, on average, $4.4 \%$ after the construction announcement and $4.3 \%$ after the location of the stations became known.

Table 2: Degree of Anticipated Differential Capitalization for Announcement and Basic Engineering stages of the construction of the new Line 4

\begin{tabular}{|c|c|c|c|c|c|c|c|c|}
\hline \multirow[b]{2}{*}{ Variables } & $(1)$ & $(2)$ & $(3)$ & $(4)$ & $(5)$ & $(6)$ & (7) & $(8)$ \\
\hline & \multicolumn{4}{|c|}{$\mathrm{T}=$ Announcement } & \multicolumn{4}{|c|}{$\mathrm{T}=$ Basic Engineering } \\
\hline Announcement & $\begin{array}{c}0.0360^{* *} \\
(0.0161)\end{array}$ & & $\begin{array}{l}0.0141 \\
(0.0166)\end{array}$ & & & & & \\
\hline Basic engineering & & & & & $\begin{array}{c}0.0531^{* * *} \\
(0.0132)\end{array}$ & & $\begin{array}{r}0.0345^{*} \\
(0.0135)\end{array}$ & \\
\hline$T * D 1000$ & & & $\begin{array}{c}0.0444^{* * *} \\
(0.00957)\end{array}$ & & & & $\begin{array}{r}0.0429^{* *} \\
(0.0103)\end{array}$ & \\
\hline$T{ }^{*}$ La Florida & & $\begin{array}{c}0.245^{* * *} \\
(0.0526)\end{array}$ & & $\begin{array}{c}0.197^{* * *} \\
(0.0575)\end{array}$ & & $\begin{array}{c}0.0942^{* * *} \\
(0.0258)\end{array}$ & & $\begin{array}{l}0.0376 \\
(0.0399)\end{array}$ \\
\hline$T *$ Penalolen & & $\begin{array}{c}0.378^{* * *} \\
(0.0539)\end{array}$ & & $\begin{array}{c}0.550^{* * *} \\
(0.0695)\end{array}$ & & $\begin{array}{c}0.565^{* * *} \\
(0.0766)\end{array}$ & & $\begin{array}{c}0.728^{* * *} \\
(0.0821)\end{array}$ \\
\hline$T *$ Nunoa & & $\begin{array}{c}0.0477^{* *} \\
(0.0207)\end{array}$ & & $\begin{array}{c}0.0642^{* * *} \\
(0.0213)\end{array}$ & & $\begin{array}{c}0.0488^{* * *} \\
(0.0153)\end{array}$ & & $\begin{array}{c}0.0518^{* * *} \\
(0.0155)\end{array}$ \\
\hline$T *$ La Reina & & $\begin{array}{c}-0.153^{* *} \\
(0.0624)\end{array}$ & & $\begin{array}{c}-0.240^{* * *} \\
(0.0678)\end{array}$ & & $\begin{array}{c}-0.153^{* * *} \\
(0.0417)\end{array}$ & & $\begin{array}{c}-0.238^{* * *} \\
(0.0500)\end{array}$ \\
\hline$T *$ Providencia & & $\begin{array}{l}0.0413 \\
(0.0276)\end{array}$ & & $\begin{array}{r}-0.0140 \\
(0.0294)\end{array}$ & & $\begin{array}{l}0.0142 \\
(0.0212)\end{array}$ & & $\begin{array}{c}-0.0387^{*} \\
(0.0229)\end{array}$ \\
\hline$T *$ Las Condes & & $\begin{array}{c}-0.00948 \\
(0.0260)\end{array}$ & & $\begin{array}{c}-0.0525^{*} \\
(0.0275)\end{array}$ & & $\begin{array}{l}0.0329 \\
(0.0202)\end{array}$ & & $\begin{array}{c}-0.00340 \\
(0.0220)\end{array}$ \\
\hline$T *$ D1000* La Florida & & & & $\begin{array}{c}0.0737^{* *} \\
(0.0355)\end{array}$ & & & & $\begin{array}{c}0.0689^{*} \\
(0.0387)\end{array}$ \\
\hline$T *$ D1000 * Penalolen & & & & $\begin{array}{c}-0.409^{* * *} \\
(0.0982)\end{array}$ & & & & $\begin{array}{c}-0.499^{* * *} \\
(0.162)\end{array}$ \\
\hline$T *$ D1000* Nunoa & & & & $\begin{array}{c}-0.0604^{* * *} \\
(0.0175)\end{array}$ & & & & $\begin{array}{c}-0.0429^{* *} \\
(0.0184)\end{array}$ \\
\hline$T * D 1000 *$ La Reina & & & & $\begin{array}{c}0.181^{* * *} \\
(0.0429)\end{array}$ & & & & $\begin{array}{c}0.198^{* * *} \\
(0.0475)\end{array}$ \\
\hline$T *$ D1000 * Providencia & & & & $\begin{array}{c}0.0964^{* * *} \\
(0.0179)\end{array}$ & & & & $\begin{array}{c}0.0813^{* * *} \\
(0.0196)\end{array}$ \\
\hline$T * D 1000 *$ Las Condes & & & & $\begin{array}{c}0.103^{* * *} \\
(0.0208)\end{array}$ & & & & $\begin{array}{c}0.0581^{* * *} \\
(0.0215)\end{array}$ \\
\hline Observations & 6857 & 6857 & 6857 & 6857 & 6857 & 6857 & 6857 & 6857 \\
\hline$R^{2}$ & 0.697 & 0.700 & 0.699 & 0.709 & 0.698 & 0.706 & 0.699 & 0.712 \\
\hline
\end{tabular}

*** $\mathrm{p}<0.01,{ }^{* *} \mathrm{p}<0.05,{ }^{*} \mathrm{p}<0.1$. Robust standard errors in parentheses. The dependent variables is the logarithm of the transaction price. This table omits all estimated coefficients for structural characteristics of the property, access to public and semi-public goods and trend. Columns (1) to (4) estimate the degree of capitalization using Announcement as treatment variable and columns (5) to (8) use Engineering as treatment variable. Columns (3) and (7) estimate equation (2) and columns (4) and (8) estimate equation (3).

The baseline models show consistently that information releases about the construction of public transit infrastructure have significant impact on housing prices, especially on the units located closer to the access points. However, the estimated average capitalization effect might 
be hiding the potential heterogeneity in the degree of capitalization across counties. As discussed before, models (2) and (4) empirically explore this possibility for the Announcement and models (6) and (8) for the Engineering. The estimation results of these models show, in general, statistically significant coefficients for the interactions of county dummies with information date dummies, which is consistent with the presence of interjurisdictional differences in capitalization.

In the case of Announcement, the results of the before-after estimator show a positive impact on apartment prices in the counties of La Florida, Peñalolen and Nuñoa with average appreciation rates of $24.5 \%, 37.8 \%$ and $4.77 \%$ respectively. These results are equivalent to say that the average apartment price increases 215 UFs in the counties of La Florida, 727 UFs in Peñalolen, and 104 UFs in Nuñoa. In contrast, the effect of Announcement is negative and statistically significant in La Reina County. On average, an apartment depreciated $15.3 \%$ after the construction announcement equivalent to an average price decrease of 324 UFs, a result not really surprising because this is a residential county whose residents have fought many times intents to build malls or even increase commercial activities in the county for the risk of an increase in criminality. Finally, the point estimator is not statistically different from zero in the counties of Providencia and Las Condes, showing a degree of capitalization not different from the average for all counties.

The results of the difference-in-difference estimator, which identifies the capitalization effect on the apartments within 1000 meters of a metro station, show a positive and statistically significant impact in the counties of La Florida, La Reina, Providencia, and Las Condes. On average, apartment values increase by $7.37 \%, 18.1 \%, 9.64 \%$, and $10.3 \%$ respectively after the construction announcement (model 4). These effects are equivalent to an average price increase of 53 UFs in La Florida, 416 UFs in La Reina, 252 UFs in Providencia, and 256 UFs in Las Condes. On the other hand, the impact is negative on apartment prices in the counties of Peñalolen and Ñuñoa. The price of apartments located within 1,000 meters from the nearest metro station in these two counties decreases 665 and 132 UFs on average after the construction 
announcement, which is equivalent to a depreciation of $40.9 \%$ and $6.04 \%$ respectively. ${ }^{6}$

The estimation results for the interjurisdictional capitalization of the information release on the location of the new Line 4 stations differ in magnitude but not in sign with respect to the impact of the construction announcement. There is a statistically significant positive impact on apartment prices in the counties of La Florida, Peñalolen and Nuñoa. The point estimators show, on average, apartment values appreciation of $9.42 \%, 56.5 \%$ and $4.88 \%$ respectively (model (6)). The opposite effect occurs in the county of La Reina, where the information of the basic engineering of Line 4 had a negative impact on housing values of $15.3 \%$. Again, in the case of Providencia and Las Condes the impact is statistically not different from zero, reflecting a capitalization effect similar to the average on all counties. Finally, the results of the difference-indifference estimator (model (8)) show a positive and statistically significant impact on apartment prices in the cases of La Florida, La Reina, Providencia, and Las Condes. The average price of an apartment located within 1,000 meters radius from the closest station appreciated respectively by $6.89 \%, 19.8 \%, 8.13 \%$, and $5.81 \%$ with respect to apartments outside that radius in the same counties. . For the counties of Peñalolen and Nuñoa the mean value of the apartments located closest to the metro stations depreciates $49.9 \%$ and $4.29 \%$ respectively.

\subsection{Non-Parametric Results}

One potential concern with the previous results based on parametric regressions is the implicit assumption of common time effects across treatment and control areas, especially across counties. Additionally, these estimators may be sensitive to differences in the covariates distributions for treated and control units. Therefore, as a robustness check of the parametric results, we also estimate the anticipated impact of the new Line 4 on apartment prices using matching estimators, which have the advantage of not requiring the use of a specific functional form.

We consider two types of matching estimators. First, we paired each treated apartment with a single or multiple non-treated apartments, comparing then the price of an apartment

\footnotetext{
${ }^{6}$ The apartment mean price is equal to 880 UFs for the county of La Florida; 1,924 for Peñalolen; 2,122 for La Reina; 2,190 for Nuñoa; 2,434 for Las Condes; and 2,594 for Providencia.
} 
after each government announcement with the price of matched apartments before the announcements. Second, we paired each treated apartment with a single or multiple non-treated apartments before and after each government announcement, considering for this purpose all apartments located within the 1,000 meters range of a metro station as treated units. Then, we compare the prices of treated and non-treated apartments before and after each announcement to obtain a non-parametric difference-in-difference estimator (Heckman, Ichimura, and Todd (1997); Heckman, Ichimura, Smith, and Todd (1998)). The first estimator is a non-parametric equivalent to the one of equation (2) and it is obtained as follows:

$$
\widehat{\eta_{2, j}}=\frac{1}{n_{1}} \sum_{i \in I_{1, t} \cap S_{p}}\left[\left(P_{i, j, t}-\sum_{i \in I_{0, t-1} \cap S_{p}} W_{i, s} P_{s, j, t-1}\right)\right]
$$

The second estimator is a non-parametric equivalent of the one in equation (3) and it is obtained as follows:

$\widehat{\eta_{2, j}}=\frac{1}{n_{1}} \sum_{i \in I_{1, t} \cap S_{p}}\left[\left(P_{i, j, t}-\sum_{i \in I_{0, t} \cap S_{p}} W_{i, s} P_{s, j, t}\right)\right]-\frac{1}{n_{1}^{\prime}} \sum_{i \in I_{1, t-1} \cap S_{p}}\left[\left(P_{i, j, t-1}-\sum_{i \in I_{0, t-1} \cap S_{p}} W_{i, s} P_{s, j, t-1}\right)\right]$

Tables 3 and 4 show the estimation results of the two types of matching estimators for the five counties using three different matching methods: nearest neighbor, stratification, and kernel. ${ }^{7}$ In general, the average treatment effects estimated by parametric methods tend to be lower than the ones estimated by non-parametric methods. For example, for the county of La Florida, the parametric estimate show an impact of $24.5 \%$ and $9.4 \%$ on apartment values after the construction and basic engineering announcements respectively; while the non-parametric estimators show an impact between $26.6 \%$ and $32.4 \%$ after the construction announcement and between $20 \%$ and $26 \%$ after the basic engineering announcement. In the case of La Reina, the average effect on apartment prices is between $-2.6 \%$ and $-4.6 \%$ after the construction an-

\footnotetext{
${ }^{7}$ The estimates satisfy the balancing property in the region of common support (see Becker and Ichino (2002)).
} 
nouncement and between $-12.9 \%$ and $-14 \%$ after the location of stations became known. It is important to mention that there are no changes in signs between the parametric and nonparametric estimators and also that on both cases there is no statistically differential effect on the counties of Las Condes and Providencia. ${ }^{8}$ The results then consistently show an anticipated effect of the new metro line announcements on apartment prices with significant differences in capitalization across counties.

Table 3: Matching estimator for the announcement of the construction of Line 4

\begin{tabular}{|c|c|c|c|c|c|c|c|c|c|c|c|c|c|c|}
\hline \multirow[b]{2}{*}{ Commune } & \multirow{2}{*}{$\begin{array}{l}\text { Matching } \\
\text { Method }\end{array}$} & \multicolumn{4}{|c|}{ Average Treatment Effects } & \multicolumn{4}{|c|}{ Control Group } & \multicolumn{4}{|c|}{ Avg. Treat. Effects on the Treated } & \multirow[b]{2}{*}{ DID } \\
\hline & & $\begin{array}{c}\text { No. } \\
\text { Treated }\end{array}$ & $\begin{array}{c}\text { No. } \\
\text { Controls } \\
\end{array}$ & ATE & s.e. ${ }^{* *}$ & $\begin{array}{c}\text { No. } \\
\text { Treated }\end{array}$ & $\begin{array}{c}\text { No. } \\
\text { Controls }\end{array}$ & ATE & s.e.** & $\begin{array}{c}\text { No. } \\
\text { Treated }\end{array}$ & $\begin{array}{c}\text { No. } \\
\text { Controls }\end{array}$ & ATE & s.e.** & \\
\hline \multirow{3}{*}{ La Florida } & Nearest Neighbor & 119 & 15 & 0.324 & 0.091 & n.a. & n.a. & n.a. & n.a. & n.a. & n.a. & n.a. & n.a. & n.a. \\
\hline & Stratitification & 113 & 31 & 0.325 & 0.134 & n.a. & n.a. & n.a. & n.a. & n.a. & n.a. & n.a. & n.a. & n.a. \\
\hline & Kernel & 119 & 25 & 0.266 & 0.094 & n.a. & n.a. & n.a. & n.a. & n.a. & n.a. & n.a. & n.a. & n.a. \\
\hline \multirow{3}{*}{ La Reina } & Nearest Neighbor & 124 & 15 & -0.461 & 0.137 & 77 & 6 & -0.427 & 0.104 & 37 & 4 & 0.171 & 0.231 & 0.427 \\
\hline & Stratitification & 108 & 46 & -0.559 & 0.252 & n.a. & n.a. & n.a. & n.a. & n.a. & n.a. & n.a. & n.a. & n.a. \\
\hline & Kernel & 124 & 30 & -0.263 & 0.090 & 77 & 10 & -0.428 & 0.108 & 37 & 11 & 0.166 & 0.243 & 0.428 \\
\hline \multirow{3}{*}{ Las Condes } & Nearest Neighbor & 626 & 122 & -0.042 & 0.068 & 348 & 60 & 0.160 & 0.217 & 278 & 47 & 0.168 & 0.078 & 0.168 \\
\hline & Stratitification & 626 & 171 & -0.044 & 0.057 & 347 & 86 & -0.001 & 0.119 & 278 & 71 & 0.123 & 0.072 & 0.123 \\
\hline & Kernel & 626 & 171 & -0.029 & 0.045 & 348 & 85 & -0.002 & 0.093 & 278 & 71 & 0.084 & 0.060 & 0.084 \\
\hline \multirow{3}{*}{ Nunoa } & Nearest Neighbor & 743 & 139 & 0.058 & 0.062 & 558 & 78 & 0.050 & 0.069 & 185 & 40 & 0.278 & 0.131 & 0.278 \\
\hline & Stratitification & 743 & 172 & 0.022 & 0.043 & 558 & 112 & 0.012 & 0.045 & 185 & 57 & 0.292 & 0.101 & 0.292 \\
\hline & Kernel & 743 & 172 & 0.084 & 0.036 & 558 & 110 & 0.019 & 0.049 & 185 & 57 & 0.197 & 0.067 & 0.197 \\
\hline \multirow{3}{*}{ Providencia } & Nearest Neighbor & 560 & 116 & -0.008 & 0.050 & 245 & 35 & -0.092 & 0.266 & 306 & 71 & 0.104 & 0.066 & 0.104 \\
\hline & Stratitification & 559 & 146 & 0.073 & 0.048 & 254 & 51 & 0.066 & 0.143 & 305 & 94 & 0.096 & 0.075 & n.a.* \\
\hline & Kernel & 560 & 145 & 0.078 & 0.048 & 254 & 51 & 0.097 & 0.122 & 306 & 93 & 0.108 & 0.068 & 0.108 \\
\hline
\end{tabular}

n.a.*: not available. The estimated coefficients are not statistically significant.

s.e.**: Bootstrapped standar errors.

Table 4: Matching estimator for the basic engineering project

\begin{tabular}{|c|c|c|c|c|c|c|c|c|c|c|c|c|c|c|}
\hline \multirow[b]{2}{*}{ Commune } & \multirow{2}{*}{$\begin{array}{l}\text { Matching } \\
\text { Method }\end{array}$} & \multicolumn{4}{|c|}{ Average Treatment Effects } & \multicolumn{4}{|c|}{ Control Group } & \multicolumn{4}{|c|}{ Avg. Treat. Effects on the Treated } & \multirow[b]{2}{*}{ DID } \\
\hline & & $\begin{array}{c}\text { No. } \\
\text { Treated }\end{array}$ & $\begin{array}{c}\text { No. } \\
\text { Controls }\end{array}$ & ATE & s.e.** & $\begin{array}{c}\text { No. } \\
\text { Treated }\end{array}$ & $\begin{array}{c}\text { No. } \\
\text { Controls }\end{array}$ & ATE & s.e.** & $\begin{array}{c}\text { No. } \\
\text { Treated }\end{array}$ & $\begin{array}{c}\text { No. } \\
\text { Controls }\end{array}$ & ATE & s.e.** & \\
\hline \multirow{3}{*}{ La Florida } & Nearest Neighbor & 389 & 79 & 0.241 & 0.055 & 102 & 8 & 0.108 & 0.107 & 214 & 44 & 0.450 & 0.069 & 0.069 \\
\hline & Stratitification & 388 & 127 & 0.220 & 0.050 & 97 & 14 & 0.146 & 0.235 & 214 & 97 & 0.388 & 0.096 & 0.096 \\
\hline & Kernel & 389 & 126 & 0.197 & 0.046 & 102 & 9 & 0.102 & 0.126 & 214 & 97 & 0.329 & 0.076 & 0.076 \\
\hline \multirow{3}{*}{ La Reina } & Nearest Neighbor & 207 & 58 & -0.140 & 0.054 & 109 & 20 & -0.119 & 0.053 & 81 & 31 & 0.026 & 0.088 & 0.119 \\
\hline & Stratitification & 207 & 89 & -0.132 & 0.056 & 109 & 24 & -0.144 & 0.068 & 81 & 31 & 0.034 & 0.080 & 0.144 \\
\hline & Kernel & 207 & 89 & -0.129 & 0.048 & 109 & 24 & -0.143 & 0.044 & 81 & 48 & 0.040 & 0.070 & 0.143 \\
\hline \multirow{3}{*}{ Las Condes } & Nearest Neighbor & 1279 & 355 & 0.055 & 0.035 & 699 & 189 & -0.039 & 0.069 & 580 & 153 & 0.092 & 0.046 & 0.092 \\
\hline & Stratitification & 1279 & 474 & 0.013 & 0.031 & 699 & 242 & 0.009 & 0.056 & 580 & 227 & 0.026 & 0.039 & n.a.* \\
\hline & Kernel & 1279 & 474 & -0.011 & 0.030 & 699 & 242 & 0.005 & 0.042 & 580 & 227 & 0.027 & 0.034 & n.a.* \\
\hline \multirow{3}{*}{ Nunoa } & Nearest Neighbor & 1411 & 330 & 0.072 & 0.026 & 1082 & 234 & 0.058 & 0.068 & 329 & 89 & 0.041 & 0.082 & n.a.* \\
\hline & Stratitification & 1411 & 511 & 0.061 & 0.034 & 1082 & 374 & 0.032 & 0.036 & 329 & 136 & 0.075 & 0.079 & n.a.* \\
\hline & Kernel & 1411 & 1411 & 0.047 & 0.024 & 1082 & 374 & 0.024 & 0.023 & 329 & 136 & 0.129 & 0.051 & 0.129 \\
\hline \multirow{3}{*}{ Providencia } & Nearest Neighbor & 1030 & 275 & -0.018 & 0.045 & 468 & 95 & -0.125 & 0.139 & 562 & 166 & -0.022 & 0.043 & n.a.* \\
\hline & Stratitification & 1030 & 361 & -0.026 & 0.046 & 466 & 126 & 0.006 & 0.068 & 561 & 234 & -0.011 & 0.048 & n.a.* \\
\hline & Kernel & 1030 & 361 & -0.006 & 0.034 & 468 & 126 & 0.003 & 0.055 & 562 & 233 & -0.002 & 0.034 & n.a.* \\
\hline
\end{tabular}

n.a.: not available. There is not counterfactual in the region of common support.

n.a.*: not available. The estimated coefficients are not statistically significant.

s.e.**: Bootstrapped standar errors.

${ }^{8}$ There are no estimates for the county of Peñalolen because in this case the means of each characteristic differ between treated and control units. 


\section{Conclusions}

The metro network is one the largest investments in public transit infrastructure in the city of Santiago. The government continues constructing new subway lines with the goal of reducing congestion and pollution in the city. Besides the potential global effects on reducing negative externalities in the city, there are some local positive effects in terms of lower commuting time and distance for residents living close to the subway stations. These benefits of the public transport services, as the theoretical have shown, should capitalize totally or in part on land property and housing prices. The empirical literature has been less successful showing that capitalization in fact occurs and the results are mixed. Additionally, most of the estimates of the effect of public transit infrastructure into housing prices implicitly assume uniform capitalization for units located at the same distance from the nearest access point. However, due to existing differences on socioeconomic characteristics and local public goods provision across counties, two identical housing units located at the same distance to the nearest metro station but in different counties (local markets) would not necessarily have the same degree of capitalization.

Given that the number of housing units possessing a particular bundle of structural and location characteristics is fixed and scarce in the short run, their prices should reflect the demand for each specific bundle. Then, a Tiebout's sorting equilibrium would lead to interjurisdictional differences in tax rates and local public goods being capitalized in housing prices. By considering the smallest administrative division providing public goods in Chile -counties-and the fact that property taxes are uniform across the country, we test whether the degree of capitalization is uniform across jurisdictions.

The results not only show a significant anticipated capitalization effect, between $3.6 \%$ and $5.3 \%$, but also identify substantial differences in magnitude across counties. The interjurisdictional differentials in capitalization are not negligible and should be considered in the debate concerning how to finance the metro network extensions. The reason is that one of the alternatives considered is to increase property taxes uniformly for all the properties located in counties serviced by the future metro lines. However, the evidence of heterogeneity in capital- 
ization rates across counties presented in this paper shows that such a policy would produce significant wealth transfers and cross-subsidies between counties.

\section{References}

Agostini, C. and Palmucci, G. (2008). "The Anticipated Capitalization Effect of a New Metro Line on Housing Prices". Fiscal Studies, Vol. 29, No. 2. (June 2008): 233-256.

Al-Mosaind, M.; Dueker, K.; and Strathman J. (1994). "Light Rail Transit Stations and Property Values: A Hedonic Price Approach". Transportation Research Record 1400: 90-94.

Armstrong, R. (1994). "Impacts of Commuter Rail Service as Reflected in Single-Family Residential Property Values". Preprint, Transportation Research Board, 73 Annual Meeting.

Bajic, V. (1983). "The Effects of a New Subway Line on Housing Prices in Metropolitan Toronto". Urban Studies 20: 147-158.

Becker, S. Ichino, A. (2002). "Estimation of average treatment effects based on propensity scores," Stata Journal, 2(4): 358-377.

Bowes, D. and Ihlanfeldt, K. (2001). "Identifying the Impacts of Rail Transit Stations on Residential Property Values". Journal of Urban Economics 50: 1-25.

Cervero, R. (1994), "Rail Transit and Joint Development: Land Markets and Impact in Washington DC and Atlanta". Journal of American Planning Association 60(1): 83-94.

Damm, D., Lerman, S., Lerner-Lam, E. and Young, J. (1980). "Response of Urban Real Estate Values in Anticipation of the Washington Metro". Journal of Transport Economics and Policy, September.

Debrezion, G., E. Pels and P. Rietveld (2003). "The Impact of Railway Stations on Residential and Commercial Property Value: A Meta Analisys". Department of Spatial Economics, Free University. Amsterdam.

Dewees, D. N. (1976). "The Effect of a Subway on Residential Property Values in Toronto". Journal of Urban Economics 3: 357-369.

Dornbusch, D. (1975). "BART-Induced Changes in Property Values and Rents, in Land Use and Urban Development Projects, Phase I, BART: Final Report". U.S. Department of Transportation and U.S. Department of Housing and Urban Development. Working Paper WP 21-5-76. 
Dueker, K., Chen, H., and Rufolo, A. (1998). "Measuring the Impact of Light Rail Systems on Single-Family Home Values". Transportation Research Record 1617: 38-43.

Gatzlaff, D. and M. Smith (1993). "The Impact of the Miami Metrorail on the Value of Residences Station Locations". Land Economics 69: 54-66.

Gibbons, S. and Machin, S. (2005). "Valuing Rail Access Using Transport Innovations". Journal of Urban Economics 57: 148-169.

Grass, R. G. (1992). "The Estimation of Residential Property Values around Transit Station Sites in Washington, D.C.". Journal of Economics and Finance 16: 139-146.

Gravel, N., A. Michelangeli, and A. Trannoy (2006), "Measuring the Social Value of Local Public Goods: An Empirical Analysis with Paris Metropolitan Area". Applied Economics 38: 1945-1961.

Goodman, A.C. (1983), "Capitalization of Property Tax Differentials within and among Municipalities". Land Economics 59(2): 211-219.

Hamilton, B.W. (1976), "Capitalization of Intrajurisdictional Differences in Local Tax Prices". American Economic Review 66(5): 743-753.

Heckman, J., Ichimura, H. and Todd, P. (1997). "Matching as an Econometric Evaluation Estimator: Evidence from Evaluating a Job Training Programme". Review of Economic Studies 64: $605-54$.

Heckman, James, Hidehiko Ichimura and Petra Todd (1998), Matching As An Econometric Evaluation Estimator, Review of Economic Studies, 65(2): 261-294.

Landis, J., W. Huang, S. Guhathukurta, and M. Zhang (1995), "Rail Transit Investments, Real Estate Values, and Land Use Change: A Comparative Analysis of Five California Rail Transit Systems", Monograph 48, Institute of Urban Studies, University of California at Berkeley.

Lee, D. B. (1973). "Case Studies and Impacts of BART on Prices of Single Family Residences". University of California, Institute of Urban and Regional Development, Berkeley, CA.

McDonald, J. and Osuji, C. (1994). "The effect of Anticipated Transportation Improvement on Residential Land Values". Regional Science and Urban Economics 25: 261-278.

McMillen, D. y McDonald, J. (2004). "Reaction of House Prices to a New Rapid Transit Line: Chicago's Midway Line, 1983-1999". Real Estate Economics 32: 463-486.

Nelson, A.C. (1992), "Effects of Elevated Heavy-Rail Transit Stations on House Prices with Respect to Income". Transportation Research Record 1359: 127-132. 
Palmon, O. and B.A. Smith (1998), "New Evidence on Property Tax Capitalization". Journal of Political Economy 106(51): 1099-1111.

Rosenbaum, P., and Rubin, D. B. (1983). "The Central Role of the Propensity Score in Observational Studies for Causal Effects". Biometrika 70: 41-55.

Vesalli, K. (1996). "Land Use Impacts of Rapid Transit: A Review of the Empirical Literature". Berkeley Planning Journal 11: 71-105.

Voith, R. (1991). "Capitalization of Local and Regional Attributes Into Wages and Rents: Differences and Mixed-Use Communities". Journal of Regional Science 31: 127-145.

Voith, R. (1993), "Changing Capitalization of CBD Oriented Transportation Systems: Evidence from Philadelphia, 1970-1988". Journal of Urban Economics 33(3): 361-376. 


\section{$9 \quad$ Appendix A}

Table A.1: Estimations Degree of Anticipated Differential Capitalization at different stages of the

construction of the new Line 4

\begin{tabular}{|c|c|c|c|c|c|c|c|c|}
\hline \multirow[b]{2}{*}{ Variables } & (1) & $(2)$ & $(3)$ & $(4)$ & $(5)$ & $(6)$ & $(7)$ & $(8)$ \\
\hline & \multicolumn{4}{|c|}{$\mathrm{T}=$ Announcement } & \multicolumn{4}{|c|}{$\mathrm{T}=$ Basic Engineering } \\
\hline DFL2 tax benefit & $0.0399 * *$ & $0.0482^{* * *}$ & $0.0332^{* *}$ & $0.0522^{* * *}$ & $0.0412^{* * *}$ & $0.0533^{* * *}$ & $0.0382 * *$ & $0.0515^{* * *}$ \\
\hline Age & $-0.0174^{* * *}$ & $-0.0174^{* * *}$ & $-0.0177^{* * *}$ & $-0.0175^{* * *}$ & $-0.0173^{* * *}$ & $-0.0172^{* * *}$ & $-0.0175^{* * *}$ & $-0.0173^{* * *}$ \\
\hline No. of bedrooms & $0.132 * * *$ & $0.134^{* * *}$ & $0.131 * * *$ & $0.137^{* * *}$ & $0.133^{* * *}$ & $0.134^{* * *}$ & $0.132 * * *$ & $0.135^{* * *}$ \\
\hline No. of bathrooms & $0.196^{* * *}$ & $0.192^{* * *}$ & $0.196^{* * *}$ & $0.185^{* * *}$ & $0.195^{* * *}$ & $0.191^{* * *}$ & $0.195^{* * *}$ & $0.187^{* * *}$ \\
\hline No. of storages & $0.122^{* * *}$ & $0.120^{* * *}$ & $0.122 * * *$ & $0.110^{* * *}$ & $0.123^{* * *}$ & $0.117^{* * *}$ & $0.124^{* * *}$ & $0.110^{* * *}$ \\
\hline No. of parking lots & $0.0843^{* * *}$ & $0.0842^{* * *}$ & $0.0836^{* * *}$ & $0.0815^{* * *}$ & $0.0842^{* * *}$ & $0.0859^{* * *}$ & $0.0834^{* * *}$ & $0.0842^{* * *}$ \\
\hline Elevator & -0.0133 & -0.0138 & -0.0195 & -0.0215 & -0.0139 & -0.0161 & -0.0202 & -0.0212 \\
\hline Change in housing stock & $-6.58 \mathrm{e}-06^{* * *}$ & $-6.80 \mathrm{e}-06^{* * *}$ & $-6.51 \mathrm{e}-06^{* * *}$ & $-7.02 \mathrm{e}-06^{* * *}$ & $-4.02 \mathrm{e}-06^{*}$ & $-4.24 \mathrm{e}-06^{*}$ & $-3.81 \mathrm{e}-06^{*}$ & $-4.77 \mathrm{e}-06^{* *}$ \\
\hline Distance to the nearest hospital & $3.13 \mathrm{e}-05^{* * *}$ & $2.94 \mathrm{e}-05^{* * *}$ & $2.77 \mathrm{e}-05^{* * *}$ & $1.11 \mathrm{e}-05$ & $2.98 \mathrm{e}-05^{* * *}$ & $1.63 \mathrm{e}-05^{*}$ & $2.76 \mathrm{e}-05^{* * *}$ & $3.48 \mathrm{e}-06$ \\
\hline Distance to the nearest clinic & $3.59 \mathrm{e}-05^{* * *}$ & $3.37 \mathrm{e}-05^{* * *}$ & $4.15 \mathrm{e}-05^{* * *}$ & $-1.74 \mathrm{e}-06$ & $3.61 \mathrm{e}-05^{* * *}$ & $1.61 \mathrm{e}-05$ & $4.07 \mathrm{e}-05^{* * *}$ & $-7.82 \mathrm{e}-06$ \\
\hline Distance to the nearest school & $1.20 \mathrm{e}-06$ & $-1.32 \mathrm{e}-05$ & $-1.93 \mathrm{e}-05$ & $-7.49 \mathrm{e}-05^{* *}$ & $-6.48 \mathrm{e}-06$ & $-3.99 \mathrm{e}-05$ & $-2.42 \mathrm{e}-05$ & $-8.42 \mathrm{e}-05^{* * *}$ \\
\hline Distance to the nearest university & $-1.79 \mathrm{e}-05^{* *}$ & $-1.85 \mathrm{e}-05^{* *}$ & $-8.38 \mathrm{e}-06$ & $2.78 \mathrm{e}-05^{* * *}$ & $-1.80 \mathrm{e}-05^{* *}$ & $-1.47 \mathrm{e}-05^{*}$ & $-1.06 \mathrm{e}-05$ & $1.15 \mathrm{e}-05$ \\
\hline Distance to the nearest green area & $8.81 \mathrm{e}-05^{* * *}$ & $7.02 \mathrm{e}-05^{* * *}$ & $9.81 \mathrm{e}-05^{* * *}$ & $2.46 \mathrm{e}-05$ & $9.00 \mathrm{e}-05^{* * *}$ & $2.10 \mathrm{e}-05$ & $9.71 \mathrm{e}-05^{* * *}$ & $-2.84 \mathrm{e}-05$ \\
\hline Located on a street & $0.0412^{* * *}$ & $0.0404^{* * *}$ & $0.0363^{* * *}$ & $0.0379 * * *$ & $0.0434^{* * *}$ & $0.0404^{* * *}$ & $0.0390^{* * *}$ & $0.0365^{* * *}$ \\
\hline Located on a side street & $-0.0538^{* *}$ & $-0.0562^{* *}$ & $-0.0557^{* *}$ & $-0.0580^{* *}$ & $-0.0539^{* *}$ & $-0.0564^{* *}$ & $-0.0558^{* *}$ & $-0.0587^{* *}$ \\
\hline La Reina & $0.105^{* * *}$ & $0.472^{* * *}$ & $0.123^{* * *}$ & $0.563^{* * *}$ & $0.103^{* * *}$ & $0.297^{* * *}$ & $0.118^{* * *}$ & $0.343^{* * *}$ \\
\hline Las Condes & $0.301^{* * *}$ & $0.542^{* * *}$ & $0.338^{* * *}$ & $0.644^{* * *}$ & $0.296^{* * *}$ & $0.334^{* * *}$ & $0.325^{* * *}$ & $0.389^{* * *}$ \\
\hline Nunoa & $0.202^{* * *}$ & $0.385^{* * *}$ & $0.252^{* * *}$ & $0.515^{* * *}$ & $0.195^{* * *}$ & $0.210^{* * *}$ & $0.235^{* * *}$ & $0.274^{* * *}$ \\
\hline Penalolen & $0.241^{* * *}$ & $0.154^{* * *}$ & $0.248^{* * *}$ & $0.217^{* * *}$ & $0.235^{* * *}$ & 0.00616 & $0.242^{* * *}$ & 0.0357 \\
\hline Providencia & $0.359^{* * *}$ & $0.552^{* * *}$ & $0.400 * * *$ & $0.692^{* * *}$ & $0.353^{* * *}$ & $0.404^{* * *}$ & $0.385^{* * *}$ & $0.476^{* * *}$ \\
\hline Announcement & $0.0360 * *$ & & 0.0141 & & & & & \\
\hline Basic engineering & & & & & $0.0531^{* * *}$ & & $0.0345^{* *}$ & \\
\hline$T * D 1000$ & & & $0.0444^{* * *}$ & & & & $0.0429^{* * *}$ & \\
\hline$T{ }^{*}$ La Florida & & $0.245^{* * *}$ & & $0.197^{* * *}$ & & $0.0942^{* * *}$ & & 0.0376 \\
\hline$T *$ Penalolen & & $0.378^{* * *}$ & & $0.550^{* * *}$ & & $0.565^{* * *}$ & & $0.728^{* * *}$ \\
\hline$T *$ Nunoa & & $0.0477^{* *}$ & & $0.0642^{* * *}$ & & $0.0488^{* * *}$ & & $0.0518^{* * *}$ \\
\hline$T *$ La Reina & & $-0.153^{* *}$ & & $-0.240^{* * *}$ & & $-0.153^{* * *}$ & & $-0.238^{* * *}$ \\
\hline$T *$ Providencia & & 0.0413 & & -0.0140 & & 0.0142 & & $-0.0387^{*}$ \\
\hline$T *$ Las Condes & & -0.00948 & & $-0.0525^{*}$ & & 0.0329 & & -0.00340 \\
\hline$T * D 1000 *$ La Florida & & & & $0.0737^{* *}$ & & & & $0.0689^{*}$ \\
\hline$T * D 1000 *$ Penalolen & & & & $-0.409^{* * *}$ & & & & $-0.499^{* * *}$ \\
\hline$T * D 1000 *$ Nunoa & & & & $-0.0604^{* * *}$ & & & & $-0.0429^{* *}$ \\
\hline$T{ }^{*} D 1000 *$ La Reina & & & & $0.181^{* * *}$ & & & & $0.198^{* * *}$ \\
\hline$T *$ D1000 * Providencia & & & & $0.0964^{* * *}$ & & & & $0.0813^{* * *}$ \\
\hline$T *$ D1000* Las Condes & & & & $0.103^{* * *}$ & & & & $0.0581^{* * *}$ \\
\hline Trend & $-0.00159^{* * *}$ & $-0.00144^{* * *}$ & $-0.00158^{* * *}$ & $-0.00120^{* * *}$ & $-0.00269^{* * *}$ & $-0.00203^{* * *}$ & $-0.00273^{* * *}$ & $-0.00163^{* * *}$ \\
\hline Constant & $6.846^{* * *}$ & $6.670^{* * *}$ & $6.815^{* * *}$ & $6.595^{* * *}$ & $6.796^{* * *}$ & $6.837^{* * *}$ & $6.767^{* * *}$ & $6.834^{* * *}$ \\
\hline Observations & 6857 & 6857 & 6857 & 6857 & 6857 & 6857 & 6857 & 6857 \\
\hline$R^{2}$ & 0.697 & 0.700 & 0.699 & 0.709 & 0.698 & 0.706 & 0.699 & 0.712 \\
\hline
\end{tabular}

